\title{
A single blind randomised placebo controlled clinical trial of a classical Ayurvedic formulation Ashokarista in the treatment of menorrhagia and dysmenorrhoea
}

\author{
Yasmeen Akhtar ${ }^{1}$, Mahiuddin Alamgir, ${ }^{2,4, *}$, Mahmud Tareq Hassan Khan ${ }^{3}$, JMA. Hannan ${ }^{1}$ and M \\ Shahabuddin Kabir Choudhuri ${ }^{1}$ \\ ${ }^{1}$ Department of Pharmacy, Jahangirnagar University, Dhaka, Bangladesh; ${ }^{2}$ Pharmacy Discipline, Khulna \\ University, Khulna, Bangladesh; ${ }^{3}$ Department of Pharmacy, University of Science and Technology, Chittagong, \\ Bangladesh; ${ }^{4}$ School of Chemistry, The University of New South Wales, Sydney, NSW-2052, Australia
}

\begin{abstract}
SUMMARY
A well known Ayurvedic formulation Ashokarista, used for menstrual disorders has been studied in a single blind randomised placebo controlled clinical trial for the treatment of menorrhagia and dysmenorrhoea. Dysmenorrhoea and menorrhagia patients who were taking Ashokarista (20 ml twice daily) for 10 menstrual cycles had an increase in haemoglobin level. Menorrhagia treated group has shown to reduce the erythrocyte sedimentation rate level that has been increased in the menorrhagia control group. The platelet count, total count and differential count were observed unchanged in the study. The Ashokarista did not affect the SGPT and SGOT level, which signify its lack of toxicity in hepatic function. The treated menorrhagic patients showed an increase in serum albumin content and decrease in blood clotting time, whereas the serum protein content was observed unchanged. There was a significant increase in both serum cholesterol and triglyceride level, which usually associated with the use of oral contraceptives. No major side effects were observed by the clinicians during the study.
\end{abstract}

Key words: Ashokarista; Menorrhagia; Dysmenorrhoea; Saraca asoca; Clinical trial; Ayurvedic

\section{INTRODUCTION}

Dysmenorrhoea or painful menstruations are an abdominal pain stemming from uterine cramps during a menstrual period and a common gynaecologic complaint (Lewis and Elvin-Lewis, 2003). It has been reported that dysmenorrhoea affects $40-95 \%$ of menstruating women (Jones, 2004). Excessive prostaglandin production and

\footnotetext{
*Correspondence: Mahiuddin Alamgir, Pharmacy Discipline, Khulna University, Khulna, Bangladesh. School of Chemistry, The University of New South Wales, Sydney, NSW-2052, Australia.

E-mail: m19alamgir@yahoo.com
}

the consequent prostaglandin induced myometrial hyperactivity are the basis for painful menstruation (Ylikokala, 1978). Menorrhagia is manifested by excessive bleeding (> $80 \mathrm{ml} /$ cycle) and is due to impaired progesterone production because of failure of the corpus luteum to develop. It is estimated that approximately $30 \%$ of women complain of menorrhagia (Bowman, 1980; Oehler and Rees, 2003). Thus dysmenorrhoea and menorrhagia are an important health care problem for women. Common treatment for dysmenorrhoea is NSAIDs or oral contraceptive pills which both work by reducing myometrial activity. The combined oral contraceptive pills, prostaglandin 
inhibitors and tranexamic acid are first line of therapy for menorrhagia. The efficacy of conventional treatments is considerable; however the failure rate is still often $20-25 \%$. Many consumers are now seeking alternatives to conventional medicines (Wilson and Murphy, 2001; Tapanainen, 2004).

Several plants have shown as a source of human hormone synthesis and have been used in menstrual disorders (Lewis and Elvin-Lewis, 2003). Ayurvedic medical treatment involves with complex combinations of several herbs. In some cases, the medicinal value of the preparation may be due entirely to the combination of constituents and cannot be reproduced by one or two so called active principles alone. This medical benefit was observed because of the mix of constituents that have synergistic effects and act upon different molecular targets (Williamson, 2001; Wagner, 2004). Ashokarista is a well known Ayurvedic medicine consists of 13 medicinal plants (Table 1 ), traditionally used in India, Bangladesh and Sri Lanka for the treatment of menorrhagia and dysmenorrhoea,. It controls the excessive bleeding and cures the pain in uterine area (Middelkoop and Labadie, 1985; Anonymus, 1992). We have previously reported the neuropharmacological activity of Ashokarista (Akhtar et al., 2001). The aim of the present study was to investigate the clinical effectiveness of Ashokarista for the treatment of dysmenorrhoea and menorrhagia.

\section{MATERIALS AND METHODS}

\section{Preparation of the drug}

The Ashokarista (ASK) was purchased from the Shakti Aushadhalaya a licensed Ayurvedic manufacturer of Bangladesh and was prepared according to the Bangladesh National Formulary of Ayurvedic Medicine (Anonymus, 1992). The test medication was manufactured in liquid form according to Good Manufacturing Practice (GMP). The plants were authenticated by the Bangladesh National Herbarium, Dhaka, where voucher specimens were deposited and in-process and quality control for the preparation was strictly controlled and monitored by the experienced officials of Shakti Aushadhalaya.

\section{Study design}

A single blind placebo controlled randomized clinical trial of Ashokarista was undertaken in 12 patients of dysmenorrhoea, 12 patients of menorrhagia

Table 1. Composition of the Ayurvedic formulation Ashokarista

\begin{tabular}{lccc}
\hline Name of the components & Family & Parts used & Amount \\
\hline Saraca asoca (Roxb.) De Wilde. & Fabaceae & Bark & $10 \mathrm{~kg}$ \\
Woodfordia fruticosa (L.) Kurz. & Lythraceae & Flower & $1.6 \mathrm{~kg}$ \\
Nigella sativa L. & Ranunculaceae & Seed & $100 \mathrm{~g}$ \\
Cyperus rotundus L. & Cyperaceae & Rhizome & $100 \mathrm{~g}$ \\
Zingiber officinale Roscoe & Zingiberaceae & Rhizome & $100 \mathrm{~g}$ \\
Berberis aristata DC. & Berberidaceae & Wood & $100 \mathrm{~g}$ \\
Nymphaea lotus L. & Nymphaeaceae & Root/Flower & $100 \mathrm{~g}$ \\
Terminalia chebula Retz. & Combretaceae & Fruit rind & $100 \mathrm{~g}$ \\
Terminalia bellirica (Gaertn.) Roxb. & Combretaceae & Fruit rind & $100 \mathrm{~g}$ \\
Phyllanthus emblica L. & Euphorbiaceae & Fruit rind & $100 \mathrm{~g}$ \\
Mangifera indica L. & Anacardiaceae & Seed kernel & $100 \mathrm{~g}$ \\
Adhatoda vasica Nees & Acanthaceae & Bark & $100 \mathrm{~g}$ \\
Pterocarpus santalinus L.f. & Fabaceae & Wood & $100 \mathrm{~g}$ \\
Molasses & - & - & $20 \mathrm{~kg}$ \\
Water & - & - & 1001 \\
\hline
\end{tabular}


and 6 normal healthy female volunteers to represent the control group. The patients were taken from the heath workers of Gonoshashthaya Medical Centre, Dhamrai, Dhaka. They were all informed of the study and were fully willing to participate in this study. Written informed consent was taken from the patients. The ethical clearance was obtained from the Gonoshashthaya Hospital, Savar, Dhaka.

During the clinical study the patients were randomized $(n=6)$ in the following five groups, dysmenorrhoea control (DC), dysmenorrhoea treated with Ashokarista (DT), menorrhagia control (MC), menorrhagia treated with Ashokarista (MT), and control group (CG). Ashokarista was given in two doses $20 \mathrm{ml}$ each, taken daily after meal for ten menstrual cycles to the treated groups. Rest of the groups was given placebo in a similar bottle and could not be distinguished one from another.

Inclusion criteria were unmarried, aged between 18 - 24 years, suffered from either dysmenorrhoea or menorrhagia. Exclusion criteria were chronic or major diseases, medicated with any other drugs, pregnancy/lactation, smoking. The patients were asked to record any symptoms and other indicators of ill health as contained in their prescribed form. Patients were assessed clinically during their monthly visits to the clinic.

\section{Biochemical procedure}

Blood was taken from each patient pre trial and at the end of the trial. Blood was immediately transferred into EDTA tubes and blood smears were prepared at the time of blood collection. The blood was tested for hemoglobin $(\mathrm{Hb})$, erythrocyte sedimentation rate (ESR), blood clotting time, platelet count, and total count and differential count (WBC, lymphocyte, monocyte, eosinophil, neutrophil). Hematologic evaluation was performed within $24 \mathrm{~h}$ of sample collection. $\mathrm{Hb}$ concentration was determined by a cyanmethemoglobin method following centrifugation of the lysate. WBC counts were performed using the modified NattHerrick's technique. Liver enzymes SGOT, SGPT, serum creatinine and blood urea nitrogen (BUN) were measured by colorimetric method. Nutritional and metabolic status was assessed by the concentrations of serum cholesterol, triglyceride, total protein, albumin and were measured by colorimetric method at the Gonoshashthaya Medical Centre, Dhamrai, Dhaka.

\section{Statistical analysis}

Statistical analyses were performed by SPSS 7.5 for Windows. Independent samples $t$-test and paired samples t-test were done as the test of significance where applicable. Values were considered significantly different if $P<0.05$. Data were expressed as mean \pm S.E.M.

\section{RESULTS}

The MC group patients have showed a significant decrease $(P<0.01)$ in their $\mathrm{Hb}$ level compared to pre treatment. The $\mathrm{Hb}$ level significantly improved in the Ashokarista treated group (MT) compared with the pre treatment group $(P<0.05)$. It also significantly increased when compared with the MC $(P<0.05)$ and CG $(P<0.05)$. The ESR found to be increased in the MC group compared to their pre treatment $(P<0.05)$ and post treatment CG $(P<0.05)$. The MT group had a reduced ESR than MC group $(P<0.05)$. The blood clotting time in post treatment MT group was found significantly lowered than pre treatment MT group $(P<0.01)$, and post treatment MC $(P<0.05), \mathrm{CG}(P<0.01)$ group. There was no change observed on the platelet count (Table 2). The total count and differential count of blood (WBC, lymphocyte, monocyte, eosinophil, neutrophil) had no significant changes between their pre treatment, post treatment or control group (Table 3).

In the liver function evaluated as SGOT and SGPT showed no significant changes between the groups (Table 4). The renal function evaluated as 
Table 2. Effect of Ashokarista on $\mathrm{Hb}$, ESR, blood clotting time and platelet count

\begin{tabular}{|c|c|c|c|c|c|c|c|c|}
\hline \multirow{2}{*}{$\begin{array}{l}\text { Group } \\
(\mathrm{n}=6)\end{array}$} & \multicolumn{2}{|c|}{$\mathrm{Hb}(\mathrm{g} / \mathrm{dl})$} & \multicolumn{2}{|c|}{ ESR (mm/h) } & \multicolumn{2}{|c|}{ Blood clotting time (min) } & \multicolumn{2}{|c|}{ Platelet count $\left(\times 10^{3} / \mathrm{mm}^{3}\right)$} \\
\hline & Pre & Post & Pre & Post & Pre & Post & Pre & Post \\
\hline$\overline{C G}$ & \pm 0.4 & $0 \pm$ & \pm 2.2 & $7 \pm$ & $0 \pm 0$ & \pm 0 & $6 \pm 1$ & $16 \pm$ \\
\hline DC & \pm 0.20 & $6 \pm$ & 2.81 & \pm & $1 \pm$ & 9 & 14 & $392.33 \pm$ \\
\hline $\mathrm{D}$ & \pm 0.42 & $17 \pm 0$ & \pm 1.68 & $7 \pm 2.60$ & $33 \pm$ & \pm 1.09 & $10.33 \pm$ & $405.83 \pm$ \\
\hline $\mathrm{N}$ & $8 \pm 0.30$ & $8.50 \pm 0.22^{\mathrm{d}}$ & $.00 \pm 4.42$ & $17.08 \pm 3.41^{\mathrm{b}, \mathrm{e}}$ & $7.55 \pm 1.03$ & $8.66 \pm 1.02$ & $399.16 \pm 10.19$ & $386.33 \pm 27.79$ \\
\hline MT & $10.26 \pm 0.55$ & $12.50 \pm 0.92^{\mathrm{b}, \mathrm{c}, \mathrm{e}}$ & $13.33 \pm 5.76$ & $10.50 \pm 2.63^{c}$ & $8.66 \pm 1.22$ & $5.83 \pm 0.70^{\mathrm{a}}$ & $386.66 \pm 19.15$ & $427.16 \pm 7.97$ \\
\hline
\end{tabular}

${ }^{\mathrm{a}} \mathrm{P}<0.01$ post treatment compared with control, ${ }^{\mathrm{b}} \mathrm{P}<0.05$ post treatment compared with control, ${ }^{\mathrm{c}} P<0.05 \mathrm{MC}$ compared with MT, ${ }^{\mathrm{d}} P<0.01$ pre treatment compared with post treatment, ${ }^{\mathrm{e}} P<0.05$ pre treatment compared with post treatment.

Table 3. Effect of Ashokarista on WBC, lymphocyte, monocyte, eosinophil and neutrophil count

\begin{tabular}{|c|c|c|c|c|c|c|c|c|}
\hline \multirow{2}{*}{$\begin{array}{l}\text { Group } \\
(\mathrm{n}=6)\end{array}$} & $\mathrm{WBC}\left(\mathrm{EE} 10^{3} / \mathrm{mm}^{3}\right)$ & Lymphocyte (\%) & \multicolumn{2}{|c|}{ Monocyte (\%) } & \multicolumn{2}{|c|}{ Eosinophil (\%) } & \multicolumn{2}{|c|}{ Neutrophil (\%) } \\
\hline & Post & Post & Pre & Post & Pre & Post & Pre & Post \\
\hline & $64 \pm$ & & & & & & & \\
\hline & $x$ & & & & & & & \\
\hline & $6.86 \pm$ & 0012.0200 & & & & & & \\
\hline & $.00 \pm 0.707 .31 \pm 0$ & $16 \pm 3.5937 .33 \pm$ & $0+0$ & 2.00 & 2.0 & 2.0 & & $7+4$ \\
\hline MT & $5.15 \pm 5.115 .85 \pm 0.4$ & $8.66 \pm 2.1738 .33 \pm 1$ & $66 \pm 0$ & $2.33 \pm 0.7$ & $2.00 \pm 0.71$ & $2.33 \pm 0$ & $9.33 \pm$ & \pm 3.53 \\
\hline
\end{tabular}

Table 4. Effect of Ashokarista on liver function

\begin{tabular}{ccccc}
\hline \multirow{2}{*}{$\begin{array}{c}\text { Group } \\
(\mathrm{n}=6)\end{array}$} & Pre & Post & SGPT (IU/1) \\
\cline { 2 - 5 } CG & $40.83 \pm 4.90$ & $36.00 \pm 4.07$ & $41.66 \pm 8.36$ & $40.17 \pm 8.03$ \\
DC & $36.17 \pm 4.58$ & $35.83 \pm 5.47$ & $41.16 \pm 6.88$ & $40.00 \pm 7.92$ \\
DT & $39.00 \pm 5.17$ & $38.17 \pm 4.78$ & $35.16 \pm 3.92$ & $32.00 \pm 5.92$ \\
MC & $35.00 \pm 2.58$ & $33.50 \pm 2.58$ & $33.83 \pm 2.33$ & $32.00 \pm 1.98$ \\
MT & $40.83 \pm 4.90$ & $36.00 \pm 4.07$ & $41.66 \pm 8.36$ & $40.17 \pm 8.03$ \\
\hline
\end{tabular}

Table 5. Effect of Ashokarista on renal function

\begin{tabular}{ccccc}
\hline \multirow{2}{*}{$\begin{array}{c}\text { Group } \\
(\mathrm{n}=6)\end{array}$} & \multicolumn{2}{c}{ Creatinine $(\mathrm{mg} / \mathrm{dl})$} & \multicolumn{2}{c}{ BUN (mg/dl) } \\
\cline { 2 - 5 } Pre & $0.66 \pm 0.06$ & $0.62 \pm 0.06$ & $16.56 \pm 2.24$ & $18.60 \pm 1.97$ \\
DC & $0.87 \pm 0.06$ & $0.82 \pm 0.05^{\mathrm{a}}$ & $13.75 \pm 0.93$ & $15.38 \pm 1.55$ \\
DT & $0.64 \pm 0.08$ & $0.75 \pm 0.08^{\mathrm{a}, \mathrm{d}}$ & $17.50 \pm 0.79$ & $26.58 \pm 2.75^{\mathrm{b}, \mathrm{c}}$ \\
MC & $0.80 \pm 0.10$ & $0.73 \pm 0.12^{\mathrm{b}}$ & $18.75 \pm 3.84$ & $25.52 \pm 4.74$ \\
MT & $0.89 \pm 0.09$ & $0.88 \pm 0.04^{\mathrm{a}}$ & $15.62 \pm 2.14$ & $22.39 \pm 2.09$ \\
\hline
\end{tabular}

${ }^{\mathrm{a}} P<0.01$ post treatment compared with control, ${ }^{\mathrm{b}} P<0.05$ post treatment compared with control, ${ }^{\mathrm{c}} P<0.01 \mathrm{DC}$ compared with DT, ${ }^{\mathrm{d}} \mathrm{P}<0.05$ pre treatment compared with post treatment.

serum creatinine showed a significant $(P<0.01)$ increase in the post treatment group of the dysmenorrhoea (DC and DT) and menorrhagia group (MC and MT) compared to the CG (Table 5). There was an increasing trend in blood urea nitrogen in the post treatment groups of the study than the pre treatment groups. This was statistically significant only in the DT group $(P<0.01)$.

The post serum cholesterol level was observed to significantly increase both in the DT and MT 
Table 6. Effect of Ashokarista on nutritional and metabolic function

\begin{tabular}{ccccccccc}
\hline \multirow{2}{*}{$\begin{array}{c}\text { Group } \\
(\mathrm{n}=6)\end{array}$} & \multicolumn{2}{c}{ Cholesterol $(\mathrm{mg} / \mathrm{dl})$} & \multicolumn{2}{c}{ Triglyceride $(\mathrm{mg} / \mathrm{dl})$} & \multicolumn{2}{c}{ Protein $(\mathrm{g} / \mathrm{dl})$} & \multicolumn{2}{c}{ Albumin $(\mathrm{g} / \mathrm{dl})$} \\
\cline { 2 - 9 } & Pre & \multicolumn{1}{c}{ Post } & Pre & Post & Pre & Post & Pre & Post \\
\hline CG & $128.04 \pm 9.25$ & $135.50 \pm 6.51$ & $82.49 \pm 19.61$ & $87.5 \pm 17.26$ & $7.84 \pm 0.31$ & $6.43 \pm 0.48$ & $4.88 \pm 0.19$ & $4.73 \pm 0.16$ \\
DC & $110.97 \pm 10.47$ & $116.66 \pm 4.59^{\mathrm{a}}$ & $88.88 \pm 17.09$ & $91.17 \pm 15.86$ & $7.94 \pm 0.30$ & $7.17 \pm 0.23$ & $4.18 \pm 0.24$ & $3.88 \pm 0.13$ \\
DT & $103.87 \pm 15.63$ & $170.33 \pm 11.16^{\mathrm{a}, \mathrm{c}, \mathrm{e}}$ & $73.88 \pm 17.68$ & $140.0 \pm 16.93^{\mathrm{b}, \mathrm{f}}$ & $7.42 \pm 0.34$ & $7.50 \pm 0.23$ & $4.07 \pm 0.16$ & $3.80 \pm 0.12$ \\
MC & $130.89 \pm 13.03$ & $135.00 \pm 9.48$ & $85.55 \pm 21.18$ & $87.58 \pm 14.18$ & $8.20 \pm 01.20$ & $7.16 \pm 0.27$ & $4.24 \pm 0.15$ & $4.01 \pm 0.41$ \\
MT & $94.33 \pm 17.19$ & $158.33 \pm 4.94^{\mathrm{a}, \mathrm{d}, \mathrm{f}}$ & $57.22 \pm 19.06$ & $108.33 \pm 11.81^{\mathrm{e}}$ & $7.33 \pm 0.23$ & $8.01 \pm 0.36$ & $3.88 \pm 0.17$ & $4.89 \pm 0.21^{\mathrm{b}, e}$ \\
\hline
\end{tabular}

${ }^{\mathrm{a}} \mathrm{P}<0.01$ post treatment compared with control, ${ }^{\mathrm{b}} \mathrm{P}<0.05$ post treatment compared with control, ${ }^{\mathrm{c}} P<0.01 \mathrm{DC}$ compared with DT, ${ }^{\mathrm{d}} P<0.05 \mathrm{MC}$ compared with MT, ${ }^{\mathrm{e}} P<0.01$ pre treatment compared with post treatment, ${ }^{\mathrm{f}} P<$ 0.05 pre treatment compared with post treatment.

group compared to the CG $(P<0.01)$, and also with their pre treatment and respective control group $(P<0.01-0.05)$. The triglyceride level was observed higher in the DT $(P<0.05)$ and MT $(P<$ $0.01)$ compared to their pre treatment and CG group. The protein level was statistically unchanged in the experiment. The albumin level was significantly higher in the post treatment group of MT compared to pre treatment MT $(P<0.01)$ and post treatment CG $(P<0.05)$ group (Table 6$)$.

\section{DISCUSSION}

Dysmenorrhoea and menorrhagia patients who were taking Ashokarista for 10 menstrual cycles had an increase in haemoglobin level compared to control and pre treatment group, thus it has a beneficial effect in anaemia to the patients with menstrual disorders. MT group have shown to reduce the ESR level that has been increased in the $\mathrm{MC}$ group, suggesting Ashokarista may have some effect in the prevention of infection process. But the platelet count, total count and differential count was observed unchanged in the study. The Ashokarista did not affect the SGPT and SGOT levels indicate that Ashokarista might not exert any toxic effect on the hepatic system. The increased serum creatinine and blood urea nitrogen level in this study was considered not related to renal function, as the level was unchanged compared to their pre treatment group. Excessive tissue protein catabolism may be responsible here for this activity and similar results were also reported during estrogen administration (Sonnnenwirth, 1982). There was a significant increase in both serum cholesterol and triglyceride level. This hyperlipidaemia is not new and usually associated with the use of oral contraceptives (Wynn, 1979). No major side effects were observed by the clinicians during the study.

It has been reported that the main ingredient of Ashokarista, Saraca asoca inhibited the $\mathrm{PGH}_{2}$ synthetase which has been responsible for the menstrual problems, and may explain the mode of action in menorrhagia (Middelkoop and Labadie, 1985). In India, a decoction of the dried bark of Saraca indica (Fabaceae) is taken for various ailments of uterus (Lewis and Elvin-Lewis, 2003). This genus Saraca found to contain anthocyanins and phytosterols which have potential benefit to the uterine problems. Another major plant of the formulation Woodfordia fruticosa also reported to contain anthocyanins (Lakshmi and Chauhan, 1976; Behari et. al., 1977; Banerjee and De, 2001). There was an evolutionary kinship with anthocyanins and steroid hormones, which has a common ancestor with enzymes important in their synthesis and regulation (Baker, 1995). The volatile oil of Nigella sativa seed proved to have a relaxant effect on uterine smooth muscle. Thymoquinone, the main active constituent of the volatile oil of Nigella sativa seed reduced spontaneous contraction of isolated rat uterus (Taha, 2004). Cyperus rotundus is an ingredient of an herbal composition for 
treating gynaecological disorders (Clavey, 2004) and sesquiterpene of Cyperus rotundus showed inhibition of prostaglandin biosynthesis (Kiuchi et al., 1983). It has been found that á-cyperone was one of effective components of Cyperus rotundus rhizomes for therapy of menorrhagia (Wen et al., 2003). The crude extracts of fresh rhizomes of Zingiber officinale showed potent inhibitory activity against prostaglandinbiosynthesizing enzyme (cyclo-oxygenase and PG synthetase) in an in vitro bioassay (Kiuchi et al., 1992); Venkateshwarlu, 1997). Thus it was considered that the major herbs and some minor herbs of the formulation Ashokarista have the beneficial effects for the treatment of menorrhagia and dysmenorrhoea. Although most of the herbal drugs of the formulation and the chemical constituents and their pharmacology is known, but recent research has shown that in some cases fixed combinations of plant extracts show greater than expected medicinal benefit. (Narimanian et al., 2005). Synergistic effects of mix constituents of Ashokarista and their action upon different molecular targets may play a role in the beneficial effect of Ashokarista and justify the uses of various individual herbs. Thus the present study provided a basis for Ashokarista for its treatment in menorrhagia and dysmenorrhoea.

\section{REFERENCES}

Akthar Y, Jabbar S, Hannan JMA, Alamgir M, Choudhuri MSK, Khan MTH. (2001) Neuropharmacological study of Asokarista- an ayurvedic formulation. Orient. Pharm. Exp. Med. 1, 18-26.

Anonymous. (1992) Bangladesh National Formulary of Ayurvedic Medicine. p. 20, National Unani and Ayurvedic Formulary Committee Bangladesh, Board of Unani and Ayurvedic System of Medicine, Bangabandhu Avenue, Dhaka.

Baker ME. (1995) Endocrine activity of plant derived compounds: an evolutionary perspective. Proc. Soc. Exp. Biol. Med. 208, 131-138.

Bowman WC, Rand MJ. (1980) Textbook of Pharmacology. 2nd ed., pp. 20-22, Blackwell Scientific Publications, New York.

Clavey SW. (2004) Compositions and methods for treating gynaecological disorders. PCT Int. Appl. WO 2003-AU820 20030627.

Jones AE. (2004) Managing the pain of primary and secondary dysmenorrhoea. Nurs Times 100, 40-43.

Kiuchi F, Shibuya M, Kinoshita T, Sankawa U. (1983) Inhibition of prostaglandin biosynthesis by the constituents of medicinal plants. Chem. Pharm. Bull. 31, 3391-3396.

Kiuchi F, Iwakami S, Shibuya M, Hanaoka F, Sankawa U. (1992) Inhibition of prostaglandin and leukotriene biosynthesis by gingerols and diarylheptanoids. Chem. Pharm. Bull. 40, 387-391.

Lewis WH, Elvin-Lewis MPF. (2003) Medical Botany: Plants affecting human health. 2nd ed., pp. 521-531, John Wiley \& Sons, Hoboken, New Jersey.

Middekoop TB, Labadie RP. (1985) The action of Saraca asoca (Roxb.) De Wilde bark on the $\mathrm{PGH}_{2}$ synthetase enzyme complex of the sheep vesicular gland. Z. Naturforsch. C. J. Biosci. 40, 523-526.

Narimanian M, Badalyan M, Panosyan V, Gabrielyan E, Panossian A, Wickman G, Wagner H. (2005). Randomized trial of a fixed combination (KanJang®) ofherbal extracts containing Adhatoda vasica, Echinacea purpurea and Eleutherococcus senticocus in patients with upper respiratory tract infections. Phytomedicine 12, 539-547.

Oehler MK, Rees MCP. (2003) Menorrhagia: an update. Acta Obstet. Gynecol. Scand. 82, 405-422.

Sonnenwirth AC, Jarett L. (1982) Gradwohl's Clinical Laboratory Methods and Diagnosis. 8th ed., p. 506, CV Mosby Co., Missouri.

Taha RAM. (2004) Spasmolytic and calcium antagonist activities of thymoquinone. Egypt. J. Biomed. Sci. 16, 152-167.

Tapanainen JS. (2004) Medical management of menstrual disorders. International Congress Series, Adv. Fertility Reprod. Med. 1266, 63-68.

Venkateshwarlu V. (1997). Cyclo-oxygenase inhibitors from spices. Indian Drugs 34, 427-432.

Wagner H. (2004) Natural products chemistry and phytomedicine in the twenty-first century: new developments and challenges. pp. 26-31, Plenary Lecture, Second International Conference on Biodiversity, New Delhi. 
Wen D, Zhang R, Chen S. (2003) Separation of chemical components in Cyperus rotundus rhizomes and its effects on ovary muscular contraction of uncyophoric rats in vitro. Beijing Da Xue Xue Bao 35, 110-111.

Williamson E. (2001) Synergy and other interactions in phytomedicines. Phytomedicine 8, 401-409.

Wilson ML, Murphy PA. (2001) Herbal and dietary therapies for primary and secondary dysmenorrhoea. Cochrane Database Syst. Rev. 3, CD002124.

Wynn B. (1979) Comparison of effects of different oral contraceptive formulations on carbohydrate and lipid metabolism. Lancet 1, 1045-1049.

Ylikorkala O. (1978) New concepts in dysmenorrhoea. Am. J. Obstet. Gynecol. 130, 833. 